\title{
PRAGMATIC APPROACH UPON THE INSTITUTIONAL EDUCATIONAL VERBALINTERACTION
}

\author{
Olga Bălănescu \\ University of Bucharest
}

\begin{abstract}
The present paper intends to analyze the institutional educational verbal interaction from the pragmatics point of view, as pragmatics is that linguistic discipline focused on the dialogized communication performed by real speakers: the teacher (instructor, trainer) and his students. I was interested in emphasizing the type of verbal; interaction established during this special form of communication, the way the principles of communication are kept or broken during the dialogue between teacher and student, different types of discourse performed by the teacher while discussing with his students. I was also interested in underlining the role of the deictic elements (especially the subjective ones) in the communication performed within the didactic process of teaching-learning.

The present paper intends to outline the importance of pragmatics in achieving an efficient teaching-learning process for the both sides implied: both for the teachers who will succeed in teaching easier their subject matters, and for the students who will understand faster the theoretic concepts and thus will be able to turn them into efficient and useful knowledge for their future career. Owing to my university teaching experience, I have faced lots of situations when pragmatics helped me out. In this paper I will focus my attention upon my didactic activities performed when teaching the Romanian language for foreign students (as I also teach Pragmatics, Advertising and Politic Discourse to the Romanian students of my Faculty). The present paper contains four parts as it follows: introduction, literature review, case study and conclusions (accompanied by limitations of the paper and recommendations).
\end{abstract}

Keywords: verbal interaction, pragmatic act, verbal acts, teaching-learning process, student.

\section{Introduction}

The evolution of the nowadays society way of thinking determined by the development of the social and economic life around, implied major changes in configuring classroom teaching and learning processes. The traditional concept of teacher includes instructional designers, trainers and other educators whose main activity is to educate students, namely to prepare them for facing real professional life. They perform a new type of discourse which is able to make the students understand faster and easier the theoretic concepts: a discourse built on pragmatics basis. During the last few decades, they have all been determined to adopt new 
philosophies which embrace and support the construction of student-centered learning environments (Seifert \& Simmons, 2016, p. 1-18). A particular feature of this new trend stands for shifting the focus of teaching and learning process from the teacher and referent of the educational discourse to the learner. More and more attention is now paid to the student (who turns into an obvious object of the educational verbal interaction) in a greater extend than to the quality or quantity of the information transmitted from teacher to student. As long as the student became a totally new character submitted to the process of education, he has been also given a new part to play: namely, he has been invited to take a more active role in his own learning. This thing was made possible owing to the new type of educational discourse performed by teachers who were interested in informal and friendly, yet polite and scientific talk able to create the necessary empathy between them and their students.

\section{Literature review}

Cognitive psychology and the related fields have increasingly advanced. Thus they provided significant pieces of information regarding the desirable categories of student actions and, also verbal interactions. Specialists have shown (Tanner, Keedy, \& Galis, p. 154-157) that knowledge acquisition can be maximized within a proper learning context. They have adopted the theory of situated condition, according to which the amount of knowledge transmitted to students cannot be separated from the culture to which it belongs. Thus learning became a process of enculturation whose experts not only to be good trainers (namely, teachers), but also to assimilate the cultural universe they stand for and to be able to transmit language culture and civilization at the same time, within the specific verbal interaction they perform on pragmatics basis. As a teacher, I have noticed the importance of the so-called maxims concerning the teachinglearning process, upon which the specialists agreed (Tanner, Keedy, \& Galis, 2013, p. 154-157). These maxims reflect a kind of a constructivist type of instruction, being grounded in cognitive theories. Here are the most representative features of instruction according to the above-mentioned maxims:

- Its whole-to-part approach (in this view, the students should perceive the image of the whole task before they are submitted to accomplish sub-skills or component parts of the respective task;

- Its authentic character (in this view, instruction should be based on real world situations, so that the students will be able to recognize them and to offer other similar examples. Otherwise, the teaching-learning process may lead to oversimplifications which can easily make knowledge rigid and useless because of its being less functional; for 
instance, I have discussed with them aspects of Romanian traditions, after which I have asked them to make a similar presentation referring to their own national traditions. The result was marvelous as they had a comparative image of traditions specific to more countries (China, Turkey, Israel and Romania), fact which really improved their knowledge;

- Its flexibility towards creating a multiple perspective approach to complex problems (the students should be offered different strategies which could be flexibly applied in finding solutions to complex problems of general interest;

- Its action orientation (in this view, it is recommended that students should learn and work at the same time. There will be no barriers between the theoretic instruction and the practical one, in the sense that the more implied within their own learning the students will be, the better their final result will be. They should be given authentic environments (though they are novices) to work in as experts in order to help them in making the necessary connection between the conceptual knowledge and the procedural knowledge.

One of the most efficient approaches that is based on the principles of constructivism is problem-based learning $(P B L)$. This model is the most innovative type of verbal interaction performed on educational purpose. It is characterized by the following main features: it uses authentic problems; it creates a student-centered learning environment; it provides an active environment for the student to learn better; its aim is to make learning to be the obvious result of associating theoretic concepts with practice (Jones, Rasmunssen, \& Moffitt, 2011, p. 89-94). All these features make PBL be different from the traditional educational and instructional approaches for which content is the most important point of interest. Thus content came to be presented the first, and then a related problem came as to exemplify the theoretic concepts. Bridges and Hallinger (2010) presented five major characteristics of problem-based education, as it follows: the starting point for the teaching-learning process is a real problem. (The teacher will submit a real slice of life to his students and start discussing about it in the view of the theoretic concepts supposed to be taught, fact which means that the teacher should firstly choose an example from the life around able to exemplify the theoretic issue. Thus reality will be no longer viewed as an example or assigned as a simple exercise); students are considered to be future professionals (in the sense that they will be asked to motivate their solutions on scientific grounds); students will be trained according to acquiring professional knowledge related to real problems rather than to specific disciplines (it means that inter-disciplinary approach is encouraged at its most. They will be trained to find solutions surpassing the borders of a strict discipline and find it easy and 
necessary to embark upon entering another discipline if the solution of the pursued issue will ask him to); students will be more responsible for their instruction, education and learning (in the sense that once they are motivated to solve a real problem, they will do their best to find the solution in spite of their intellectual effort; learning will be more efficient for the students whether it occurs within a small group rather then individually or within large groups.

There are various ways a problem may be presented on the background of problem-based learning, fact which depends on the type of verbal interaction established between the instructor (teacher) and the student: by means of written cases (when it is a verbal interaction of transaction between the interlocutors); by means of vignettes containing limited information (necessary to satisfy the requests of the students for specific data); filmed episodes (which will be discussed later on, meaning that a personal verbal interaction may be established between the teacher and his students); interviews with focus groups (Bridges \& Hallinger, p. 14). The real problems may be considered to be anchors for the learning process (Jones, Rasmunssen, \& Moffitt, 2011, p. 118). These "'anchors" have been much appreciated by specialists as they "capture the imagination, be perceived as important by learners, legitimize the disciplinary content they integrate, and accommodate a variety of learning approaches" (Barab, 2016, p. 53). Such anchors of the problem based learning should be general enough in order to be pursued from various perspectives (so that both the teacher and his students, according to their individual prior experience and knowledge to be able to state his own point of view. Thus the dialogue may develop freely and friendly, and the results will be remarkable as all the participants will accomplish his main aim as Koschmann (2013, p. 201) or Feltovich (2004, p. 59) showed. Such problem-based projects can be achieved by students in the classroom in close connection with the purposes aimed at by the teacher, namely: to develop the power of selection of the students (thus the teacher will ask the students to choose from the problems listed by him according to the rank of social, economic or cultural importance); to increase the students responsibility by asking them to choose from among the problems listed by them. There can be identified more forms that the problem may take. Here are the most significant ones: an event ( a real situation); a set of questions; a descriptive statement. No matter the nature of the problem submitted to students, such project-works should follow several phases as they were outlined by Seifert and Simmons (2012, p. 72): problem formulation; data collection; brainstorming solutions; evaluating and selecting solutions; implementing the solutions; assessment. 


\section{Discussions}

I will briefly present several delicate aspects of teaching Romanian language to foreign students, aspects which I have focused upon during my didactic activity in The University of Bucharest. Thus, I have noticed that the same theoretic concepts may be differently taught according to the features of the audience (namely: age, level of culture, habits, customs, nationality, cultural universe they belong to), but making use of the same type of personal verbal interaction. We are all acquainted with the methods of learning as we are all teachers. Yet it depends on our own communicative competence and didactic diplomacy to be successful in teaching the Romanian language to the foreign students in front of us. Explanation is a method of oral communication (Cerghit, 2015) which can be much improved whether we perform it by means of our pragmatics knowledge. It turns out to be profitable for us to present a grammatical concept/category by making references to the corresponding one in the linguistic system of the students in front of us. But what if the two linguistic systems are absolutely incompatible? Actually, this is a very frequent situation in Romania, as many Arabian, Chinese or Jewish students study in Romania. Practices showed me how important it is to know pragmatics, and thus to be able to build pragmatic acts behind your proper discourse. It is well-known that the pragmatic act stands for that unspoken message which is hidden behind the words (Taylor \& Talbot, 2008, p. 19). The speaker simply suggests his interlocutor an idea, and lets him draw the conclusion by himself as "a person convinced against his will is of his opinion still" (Sutherland \& Sylvester, 2009, p. 118). Here is an example: before teaching the plural inflexions to a group of Arabian students, I will encourage them saying that this very issue is easier in Romanian language than it is in their own language where, besides singular and plural inflexions there are also dual inflexions. In other words, in Romanian language, the nouns may have only two forms (of singular and plural), while in Arabian, they meet dual besides singular and plural. The pragmatic act is that the Romanian language is easier than the Arabian one, so that the students should be happy to face a more accessible linguistic system. Once they are induced this idea, they will successfully assimilate this piece of knowledge because they will be eager to experiment something easy. Storytelling is another oral method of learning which helped me out of many other difficult problems of our Romanian grammar. This method plays two functions at the same time: both a communicative function as it is the main tool for transmitting new knowledge, and a cognitive one as it helps the student to improve his knowledge. My teaching experience showed me that there is no difficulty in teaching the adjective with four forms (masculine/neuter singular; feminine singular; masculine plural; feminine/neuter plural). Moreover, the foreign students will feel comfortable to hear that most of the Romanian adjectives have 
four distinctive inflexions. The problem starts when we, the teachers, have to explain them that there are also adjectives which develop three distinct inflexions (masculine/neuter singular; feminine singular; masculine/neuter/feminine plural), two inflexions (one for singular no matter the genre, one for the plural), as well as invariable adjectives. The problem is that the foreign students are not willing to learn by heart anything, as these three categories are constituted of several items which should be memorized as such. The scientific explanation referring to the origin of the words (whether they belong to the usual vocabulary, or to neologisms) does not work for the foreign students (the way it proves to work for the Romanian ones) for the simple reason that they are not Romanian native speakers, so that they do not realize the difference between atroce (which is a neologism, meaning fierce) and subtire (which is an ordinary word, meaning thin). They hear the both words for the first time in their lives, so they treat them just the same. The scientific explanation which have worked for the Romanian students who should easily understand that neologisms (like atroce) are invariable, while those usual adjectives ending in -e (like subtire, mare) develop two inflexions only. I was saved by story-telling. I created a little story which proved to be successful in teaching more and different nationalities of foreign students, no matter their age. So that, when teaching the adjective with 2 inflexions, the teacher should make the following steps: write the subject of the lesson on the whiteboard (The Adjective with 2 inflexions); tell the story to the students; select (out of the story) the adjectives meant to be kept in mind by students (namely, the proper subject of the lesson); write these adjectives on the whiteboard; at the end ask them: is it simple?

They have been all satisfied with the story. Here is the story: (attention! You should use for telling the story only the words they know up to that moment): you pay a visit to a friend. The host brings in two trays: there is a thin (subtire) slice of sweet (dulce), green (verde) and cold (rece) melon on one of the trays; on the other one, there is an old (veche) cup of hot (fierbinte) coffee. What do you choose? Which one do you prefer? The various types of verbal acts were of much help in building the story. The representative verbal acts proved to be necessary for outlining those specific adjectives with 2 inflexions. So the story had to be created so as to focus the attention of the students upon certain adjectives (standing for some qualities of real items). As the persons in front of me are foreign students whose life is mostly performed inside their communities (so, paying a visit is, no doubt, more frequently often performed then when being in their own countries, I have decided upon a script able to emphasize this activity.) I have also used brain-storming in various moments of the teaching-learning process like the moment of writing a composition.

As I was interested in attracting them to my city (Bucharest), as well as in informing them about it, I asked my foreign students to prepare a composition 
entitled 'Life in Bucharest'. Here are a few methodological pieces of advice: the students will associate themselves in small work teams (on friendly criteria); the teacher writes the topic on the whiteboard; the teacher will write the plan of the composition on the whiteboard; each work team will try to work individually in order to answer the requests of the plan; the students will be given a specific and clearly specified span of time for every single task (5-6 minutes for each); the teacher will watch the way they work in teams and will encourage their efforts; every team will name a colleague to present the result of their work together, and another one to write on the whiteboard; all the other groups (work teams) will write all the presentations in their copy-books; the teacher will appreciate the efforts of every single work team and will utter the final request: to write (at home) a composition able to include all the presented ideas. Pragmatics enters the stage from the very first step when I ask them to make work teams, with a view to help the students to obtain better results. This is a promise: they will associate themselves on friendly criteria, and they will pleasantly work together, they will strengthen their relationships, and get to know each other better. So that, they will be willing to perform such brainstorming activities which will be perceived to be closer to their personalities than plain, traditional learning. Thus the promising verbal acts play an important part. On the other side, working together in an informal context will make the students be open-minded to finding good solutions in order to bring a good score to their own work team. In pragmatics, the context represents the proper physical environment in which the conversation takes place, together with the specific mood of the interlocutors (Searle, 1977; Taylor \& Talbot, p. 198). It is exactly what it should be done in order to teach by focusing the attention upon the students: you, as a teacher, create them an informal context based on friendly terms, and the students will feel no constrains and will develop a real scientific dialogue, keeping a good mood and a positive and optimistic state of mind, at the same time. As they have previously informed themselves about Bucharest, they will be able to make an interesting exchange of information and opinions. So that, every single presentation will bear the fingerprint of their own personality. Thus, they will use affective verbal acts, bringing out into strong relief those aspects which are of interest for him/her. I have noticed that the girls are mostly interested in parks, gardens, fashion, contest or parades, as well as in the cultural side of life: theatres, exhibitions, concerts and traditions; boys are more preoccupied by restaurants, clubs, football teams, sports in general, motor cars and history. Once one Chinese girl spoke about the Romanian Christmas traditions, as it was something very new and interesting to her and even learned by heart some carols. Many Arabian students were interested in the history of Bucharest (including the origin of its name), as well as in the oldest buildings in Bucharest. 


\section{Limitations of These Studies}

The present article has its limitations. The strict number of pages forced me to focus my attention only upon a few aspects, while more others still wait for being tackled about. Many other curricular as well as extracurricular activities should have been taken into consideration in order to offer a complete view of the learning process.

\section{Conclusions and Further Study}

The teaching learning process has seriously developed nowadays with a view to improve the following aspects: the relationship between teacher and student (who are the performers of the teaching learning process); the self-image of every single performer; the final result. The so called problem-based learning has focused its attention upon changing the traditional specific of every performer: it is not the teacher the most important person nowadays, within the teachinglearning process, but the student, who is given an active, dynamic and personalized part to play, fact which will make the student take a direct part within the teaching-learning process. Consequently, the modern student will be more willing to accept information because he is given real problems to solve by means of his knowledge. Pragmatics proves to be more and more important nowadays as real and informal talk is more and more encouraged. By means of pragmatic acts and deictic elements of space and time, as well as by building a specific context or situational context, more efficient results can be obtained. These better results can belong both to the teachers (who succeeds in handling their students better), and to students (who become more devoted to their own scientific research). What I do recommend to further investigators is to give a special attention to pragmatics and to its communicative principles.

\section{References}

Barab, \& Sasha (2016). Games, Learners and Innovation, Mary Lou Fulton Teachers College at Arizona State University Press.

Bridges, J., \& Hallinger, L. (2010). The Didactic Dialogue, IRWIN, Homewood, Illinois. Ioan Cerghit (2015). Metode de invatamant, Editura Didactica si Pedagogica, Bucuresti.

Feltovich, Paul (2004). Dimensions of Adjustable autonomy and mixed-initiative interaction, in M. Klusch, G. Weiss, M. Rovatsos (eds.), Computational Autonomy, Berlin, Germany, Spring-Verlag.

Jones, B. F., Rasmussen, C. M., \& Moffitt, M. C. (eds), (2011). Real-life Problem solving: A Collaborative Approach to Interdisciplinary Learning, American Psychological Association, Washington D. C.

Koschmann, J., \& Timothy (2013). Qualitative Research in Psychology, Routledge, Springfield. 
Seifert, A., \& Simmons (2012). Problem-based learning in Nowadays Education, Routledge, London.

Seifert, E. H., \& Simmons, D. (2016). Learning centered schools using a problem-based approach, in Canadian Journal of Educational Communication, vol. 27, No. 1.

Searle, \& John., R. (1977). A Classification of Illocutionary Acts, in Andy Roger, Bib Wall and John P. Murphy (eds.) Proceedings of the Texas Conference on Performatives, Presupositions and Implicatures, Washington D. C. Center for Applied Linguistics.

Sutherland, Max, Sylvester, \& Alice. From Advertising to Consumer, Routledge, London, 2009.

Taylor, L., \& Talbot, L. (2008). Mutual Misunderstanding, Routledge, London.

Tanner, C. K., Keedy, J. L., \& Galis, S. A. (2013). Problem-based learning: Relating the Real World to Students Preparation, Clearing House, pages 154-157.

Whittaker, S. G., \& Scheiman, M. (2014). Problem-based teaching in a Didactic Curriculum, in Canadian Journal of Educational Communication, vol. 24, No. 4. 